\title{
Alterações histopatológicas em girinos de rã-touro alimentados com rações comerciais de diferentes níveis protéicos ${ }^{1}$
}

\author{
José Teixeira de Seixas Filho ${ }^{2,3}$, Marcio Hipolito ${ }^{4}$, Vinicius de Frias Carvalho ${ }^{2}$, Ana Maria Cristina \\ Rabello Pinto da Fonseca Martins ${ }^{4}$, Lilian Nogueira da Silva ${ }^{2}$, Airton Antonio Castagna ${ }^{2}$
}

1 Trabalho parcialmente financiado pela FAPERJ.

2 Centro Universitário Augusto Motta - UNISUAM - Av. Paris, 72 - Bonsucesso - RJ - Grupo AQÜISUAM -Laboratório de Pesquisa em Biologia.

${ }^{3}$ Fundação Instituto de Pesca do Estado do Rio de Janeiro - FIPERJ - Alameda São Boaventura, 770 - Fonseca - Niterói.

${ }^{4}$ Centro de Pesquisa e Desenvolvimento de Sanidade Animal. Instituto Biológico de São Paulo.

RESUMO - Realizaram-se necropsia e exame histopatológico de girinos de rã-touro (Rana catesbeiana) alimentados com rações comerciais formuladas com 32, 36, 45 ou 55\% de proteína bruta (PB) visando estabelecer a relação entre o nível de proteína bruta da ração e a sanidade do animal. Na necropsia, os girinos não apresentaram externamente nenhuma alteração aparente, no entanto, o fígado dos animais, em todos os níveis de proteína bruta, apresentou-se de cor palha e manchado. Na análise histopatológica, observaram-se fígados com rarefação e degeneração celular protéica, intestinos com colite e achatamento das microvilosidades; baço com hiperplasia linfocitária; coração sem nenhuma alteração; rins com glomerulonefrite e áreas de tubulonefroses; gastrite mononuclear e hiperplasia e hipertrofia dos linfonodos regionais. Em todos os órgãos, verificou-se depósito de hemossiderina. Essas lesões sugerem quadro degenerativo nutricional, com desenvolvimento de processos inflamatórios, se difundindo para todos os órgãos. Os resultados sugerem que os animais foram alimentados com rações com proteínas de baixo valor biológico, portanto, de má qualidade, o que comprometeu a sanidade e o desempenho dos animais. Estudos complementares são necessários para compreensão do comportamento bioquímico de rãs-touro na fase de girino visando à nutrição adequada desses animais.

Palavras-chave: girino, nutrição animal, patologia, rã-touro, Rana catesbeiana

\section{Histopathological alterations in bullfrog tadpoles fed commercial diets with three levels of crude protein}

\begin{abstract}
Necropsy and histological examination were made on bullfrog (Rana catesbeiana) tadpoles fed commercial rations with $32,36,45$ or $55 \%$ crude protein (CP) to establish the relationship between dietary crude protein and health of the animal. In the necropsy, the tadpoles did not show externally any changes, however, the liver of animals at all crude protein levels, presented a straw color and stained. Histological analysis showed livers with rarefaction and degeneration of cell protein, intestines, with colitis and flattening of microvilli, spleen with lymphocyte hyperplasia, heart, without alterations, kidneys with glomerulonephritis and areas of tubulonefroses; mononuclear gastritis and hyperplasia and hypertrophy of regional lymph nodes. In all organs, there was hemossiderin deposit. These injuries suggest degenerative nutritional condition, with development of inflammatory processes, spreading to all organs. The results suggest that the animals were fed diets with low biological value proteins, therefore, poor quality, which affects health and performance of the animals. Further studies are necessary to understanding the biochemical behavior of bullfrogs in the tadpole stage, aiming to adequate nutrition of these animals.
\end{abstract}

Key Words: animal nutrition, bullfrog, pathology, Rana catesbeiana, tadpole

\section{Introdução}

Na ranicultura, a criação de girinos é fundamental, no entanto, a alimentação é um problema para o criador, pois são utilizadas rações comerciais formuladas geralmente considerando as exigências nutricionais de peixes, o que pode ocasionar desenvolvimento anormal ou mortalidade, prováveis sinais de desordens nutricionais.

Autores (Culley Jr. et al., 1978; Fontanello et al., 1982; Hipolito, 2004) relataram a freqüente ocorrência de elevados índices de mortalidade nos setores de criação de girinos de rã-touro e atribuíram o fato a problemas nutricionais que causaram o aparecimento de patologias, sugerindo para 
criação plena a obtenção de formulações adequadas, principalmente quanto ao teor protéico.

Todo alimento, depois de digerido no trato intestinal, tem seus nutrientes processados a nível hepático. Entre as funções hepáticas mais importantes, destacam-se a formação de proteínas plasmáticas, a desaminação de proteínas, a formação de uréia, a formação de uréia para remoção de amônia como efeito detoxificante e a síntese de certos aminoácidos (Hipolito et al., 2004). Assim, no caso da rã-touro, uma disfunção grave neste órgão, decorrente de várias causas e por dias seguidos, pode levar a um quadro irreversível (Hipolito et al., 2001; Guyton \& Hall, 2002), com evidente diminuição da taxa de crescimento, e a morte do animal.

Boorman (1980) comentou que o balanço ideal dos aminoácidos deve ter perfil relativo o mais próximo possível daquele encontrado no produto a ser formado.

Seixas Filho et al. (2006) avaliaram o trato gastrintestinal de girinos de rã-touro (Rana catesbeiana) alimentados com rações comerciais contendo 22,24 ou $28 \%$ de proteína bruta (PB)e, por meio de cortes histológicos, sob microscopia de luz comum, observaram, no $25^{\circ}$ dia após o início da alimentação exógena (estádio 25, segundo Gosner, 1960), a presença de células hepáticas com arranjo glandular mais compacto, que sugere funcionalidade, confirmada pelos resultados de desempenho dos animais a partir deste período, que foram melhores nos girinos alimentados com ração com maior nível de proteína bruta.

Neste trabalho, avaliaram-se as alterações histopatológicas sistêmicas de girinos de rã-touro (Rana catesbeiana) alimentados com rações comerciais - com diferentes formulações e quatro níveis de proteína bruta (PB) - utilizadas em ranários do Rio de Janeiro.

\section{Material e Métodos}

O experimento foi conduzido pelo Grupo de Pesquisa AQÜISUAM, no Laboratório de Pesquisas em Biologia do Curso de Licenciatura em Ciências Biológicas da UNISUAM, Campus Bonsucesso, em Rio de Janeiro, RJ.

Durante o período experimental (60 dias), foram utilizados 480 girinos de rã-touro (Rana catesbeiana Shaw, 1802) com 15 dias, no estádio 25 de Gosner(1960), provenientes de mesma desova, com peso de $0,027 \pm 0,009 \mathrm{~g} \mathrm{e} 4,91 \pm 0,45 \mathrm{~mm}$ de comprimento.

Os animais foram distribuídos em 16 caixas plásticas com $50 \mathrm{~L}$ de capacidade, na densidade de um girino por litro de água, a qual foi mantida durante todo o experimento, retirando-se $1 \mathrm{~L}$ de água para cada animal morto, segundo Arruda Soares et al. (1983).
A água foi distribuída nas caixas por meio de tubos de PVC, com renovação de $200 \%$ do seu volume, a cada 24 horas, durante todo o período experimental. O escoamento da água era feito por meio de canaletas de PVC acondicionadas lateralmente nas bancadas e conectadas ao esgoto. O nível de água no interior das caixas foi mantido por meio de dispositivo tipo "joelho" adaptados na lateral das caixas, segundo Seixas Filho et al. (1997).

Em cada módulo experimental, houve aeração constante, mantida por meio de soprador e mangueiras plásticas 3/16', providas de pedras porosas em suas extremidades e reguladas por registro de mesmo calibre.

A ração foi fornecida aos girinos em cochos confeccionados com tubos PVC de $50 \mathrm{~mm}$, cortados no sentido do comprimento, com extensão igual à largura da caixa. Os cochos foram fixados nas laterais do módulo experimental, para que permanecessem sem movimento.

$\mathrm{Na}$ alimentação dos girinos, foram utilizadas quatro rações comerciais com $32,36,45$ ou $55 \%$ de proteína bruta, com granulometria de $0,5 \mathrm{~mm}$ (Tabela 1 ), fornecidas uma vez ao dia, às 12 horas, no cocho, na proporção de 5 a 10 g por unidade experimental, de acordo com o crescimento dos girinos, de modo a ter sempre sobra após 24 horas, para coleta e cálculo do consumo (Seixas Filho et al., 1998).

A limpeza das caixas foi realizada diariamente, por sifonagem do fundo, retirando-se as fezes e os restos de alimento. Diariamente, pela manhã e à tarde, foram tomadas as temperaturas do ar e da água por meio de termômetro de coluna de mercúrio, com escala em centígrados, de 0 a $60^{\circ} \mathrm{C}$.

Tabela 1 - Rações comerciais utilizadas na alimentação de girinos de rã-touro (Rana catesbeiana)

\begin{tabular}{lcccc}
\hline Nível de garantia & \multicolumn{4}{c}{ Proteína bruta $(\%)$} \\
\cline { 2 - 5 } & $32^{1}$ & $36^{2}$ & $45^{1}$ & $55^{3}$ \\
\hline Umidade máxima & 13 & 13 & 13 & 13 \\
Proteína bruta & 32 & 36 & 45 & 55 \\
Extrato etéreo (mínimo) & 7 & 8 & 8 & 10 \\
Matéria fibrosa (máximo) & 7 & 7 & 7 & 5 \\
Material mineral (máximo) & 2,6 & 3,1 & 3,1 & 3,0 \\
Cinzas (máximo) & 12 & 14 & 14 & 14 \\
Cálcio - Ca (máximo) & 2,0 & 2,5 & 2,5 & 2,0 \\
Fósforo - P (mínimo) & 0,6 & 0,6 & 0,6 & 1,0 \\
\hline
\end{tabular}

Composição básica: farelo de soja; farinha de peixe; farelo de trigo; farelo de glúten de milho 60\%; farinha de carne e osso; milho; farinha de sangue; óleo de peixe; carbonato de cálcio; fosfato bicálcico; sal; suplemento vitamínico ${ }^{1}$ e mineral; antioxidante ${ }^{3}$.

1 Composição por kg: vit. A - 12.000 UI; vit. $D_{3}-4.000$ UI; vit. E - 150 UI vit. K - $10 \mathrm{UI}$; ácido fólico - $10 \mathrm{mg}$; biotina - 0,8 mg; colina - $500 \mathrm{mg}$ niacina - $150 \mathrm{mg}$; pantotenato de cálcio - $50(\mathrm{mg})$; tiamina - $30 \mathrm{mg}$; riboflavina - $30 \mathrm{mg}$; piridoxina B6 - $30 \mathrm{mg}$; vit. B12 - $35 \mu \mathrm{g}$; vit.C - $300 \mathrm{mg}$.

2 Composição por kg: Mg $-700 \mathrm{mg}, \mathrm{Mn}-30 \mathrm{mg}, \mathrm{Zn}-200 \mathrm{mg}, \mathrm{Cu}-15 \mathrm{mg}$,

$\mathrm{Fe}-100 \mathrm{mg}, \mathrm{I}-1 \mathrm{mg}$, Se - 0,3 mg.

${ }^{3}$ Etoxiquina - $250 \mathrm{mg}$. 
O controle da amônia e do $\mathrm{pH}$ foi feito diariamente, por meio de titulometria e de aparelho digital, respectivamente.

Ao final do período experimental, três animais de cada repetição das quatro rações, totalizando 48 exemplares, foram acondicionados em recipientes com água a $-4^{\circ} \mathrm{C}$, objetivando a redução do metabolismo e, em seguida, foram anestesiados em solução de mentol a $10 \%$, insensibilizados por contenção fisiológica, por meio da secção transversal da medula espinhal e submetidos a necropsia para verificar a ocorrência de lesões, externas e internas, e o aspecto histopatológico, principalmente do fígado, além dos outros órgãos, com o estômago, o intestino e os rins. Os órgãos foram fixados em solução de metacarmim por 12 horas e, em seguida, foram mantidas em álcool $70 \%$. Para os exames histopatológicos, foram emblocados em parafina, cortados com $5 \mu \mathrm{m}$ de espessura em micrótomo e corados por HE (hematoxilina e eosina) para observação das lâminas sob microscopia de luz.

\section{Resultados e Discussão}

A temperatura média do ar foi 30 e $25^{\circ} \mathrm{C}$ (máximas e mínimas, respectivamente); a temperatura média da água foi de 24 a $26^{\circ} \mathrm{C}$; o pH manteve-se na faixa de 7,0 a 8,9 ; e a amônia, na faixa de 0,25 a 0,50 . Os parâmetros físico-químicos da água mantiveram-se nos limites aceitáveis para girinos e foram semelhantes às condições dos trabalhos de Fontanello et al. (1982) e Seixas-Filho et al. (1998; 2006). Portanto, as condições ambientais do experimento permitiram que os animais estivessem, durante todo o período de observação, sob condição de conforto, comprovada pela contínua alimentação dos girinos.

As proteínas são consideradas o principal constituinte de qualquer célula viva e representa o grupo químico mais abundante do corpo dos animais, à exceção da água. Proteínas são essenciais para o núcleo e citoplasma e resumidamente têm as funções de reparar tecidos danificados ou desgastados e formar novos tecidos (síntese de novas proteínas durante o crescimento). Proteínas, via alimentação, podem ser catabolizadas e atuarem como fonte de energia ou servirem de substrato para a formação de lipídios e carboidratos no tecido, bem como para a formação de hormônios, enzimas e uma variedade de substâncias importantes, como anticorpos, hemoglobina, entre outros (Tacon, 1989).

Uma vez que o fígado é o "guardião do meio interno", distúrbios hepáticos têm conseqüências de longo alcance sobre a homeostasia corpórea. A má nutrição protéicocalórica prolongada produz ampla gama de síndromes em mamíferos, inclusive comprometendo a resistência imunológica por atrofia linfóide e favorecendo a ocorrência de processos infecciosos (Figuras 1 e 2).

No exame histopatológico do fígado, observou-se grande prevalência de degeneração protéico-mineral em hepatócitos, independentemente da quantidade protéica presente na ração oferecida aos animais. Os fígados apresentaram-se macroscopicamente pálidos e microscopicamente com parênquima formado por hepatócitos com

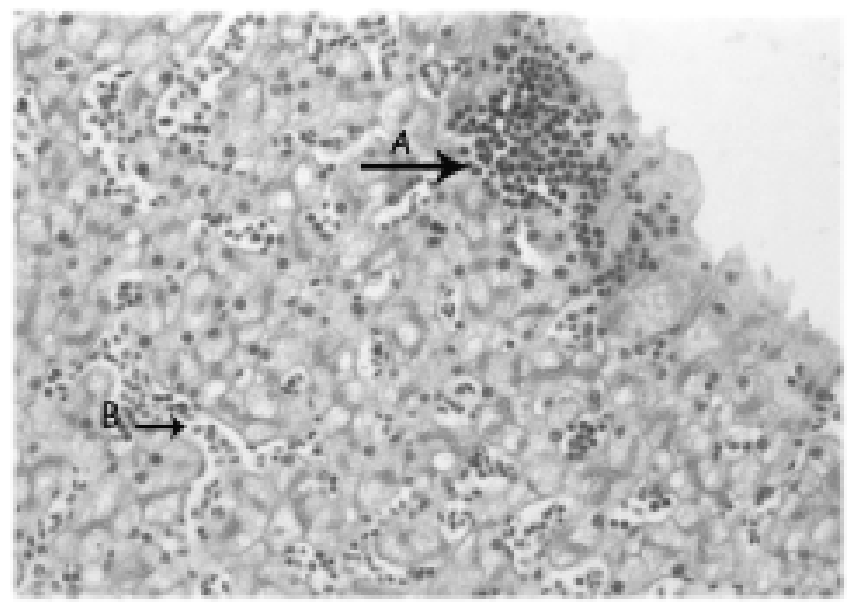

Figura 1 - Fotomicrografia de fígado de girino de rã-touro alimentado com ração de $36 \%$ de PB. Acentuada rarefação do citoplasma dos hepatócitos. Presença de células mononucleares e focos de hepatite subcapsular (seta A) e congestão dos vasos sangüíneos (seta B). Coloração com HE, 100X. As mesmas lesões foram observadas nos girinos alimentados com rações contendo 32 , 45 e $55 \%$ de PB.

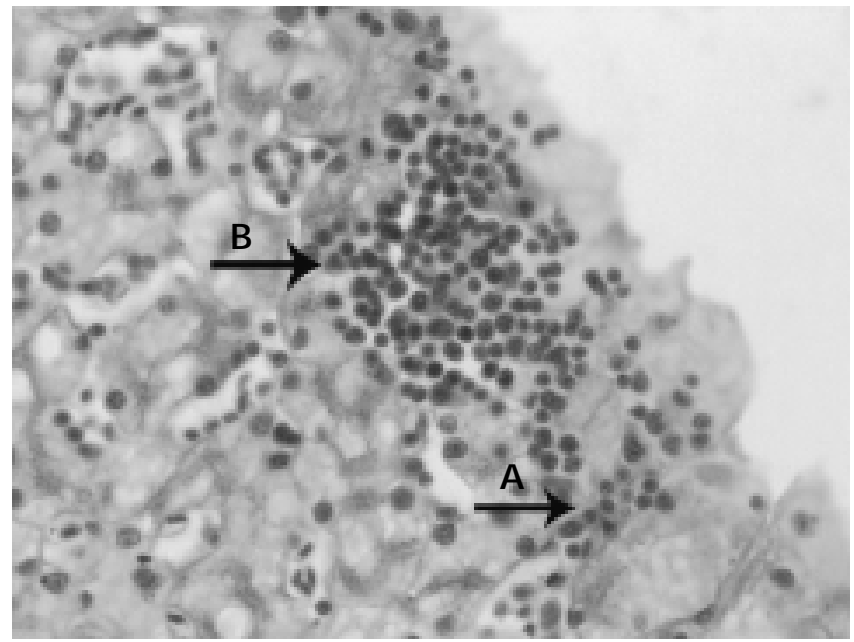

Figura 2 - Fotomicrografia de fígado de girino de rã-touro alimentado com ração de $36 \%$ de PB. Presença de hepatite mononuclear (seta $A$ ) e focos de hepatite subcapsular e intersticial (seta B). Coloração com HE, 200X. As mesmas lesões foram observadas nos girinos alimentados com rações contendo $32,45 \mathrm{e}$ $55 \%$ de $\mathrm{PB}$. 
citoplasma acentuadamente rarefeito, vacuolizados, assemelhando-se a uma renda (Figuras 1 e 2).

Nas observações, $90 \%$ dos animais analisados apresentaram falta de deposição protéica nos hepatócitos, o que permite inferir que as rações eram de má qualidade protéica, acarretando diversas patogenias nos girinos, em todos os níveis protéicos testados, após 60 dias de experimentação. Lesões de colite mononuclear, redução do índice mitótico nas criptas e glândulas associadas, perda ou achatamento dos vilos e microvilos ou hiperplasia de

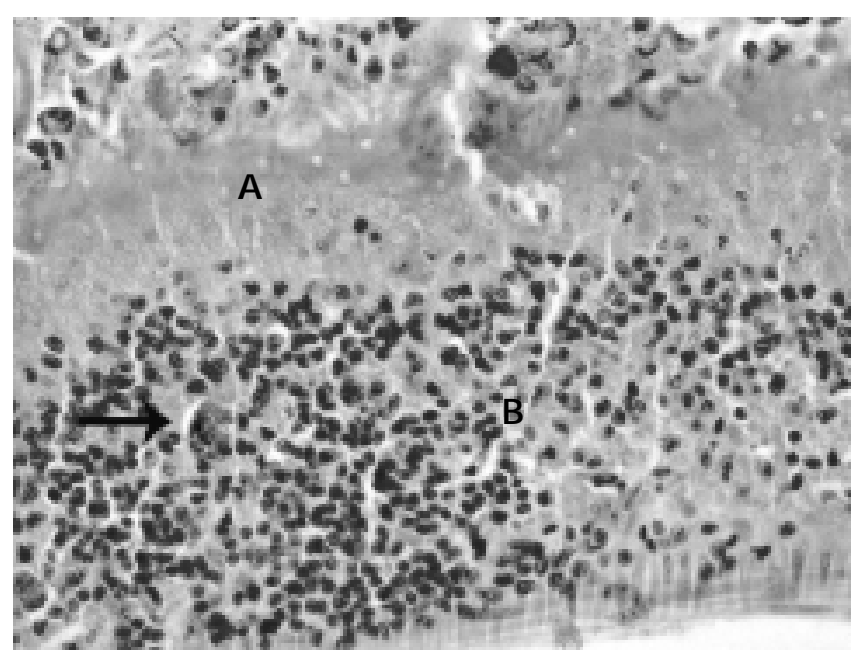

Figura 3 - Fotomicrografia de intestino posterior de girino de rãtouro alimentado com ração de $36 \%$ de PB. Presença de colite (A), hiperplasia de linfonodo (B) e hemossiderina (seta). Coloração com HE, 100X. As mesmas lesões foram observadas nos girinos alimentados com rações contendo 32 , 45 e $55 \%$ de PB.

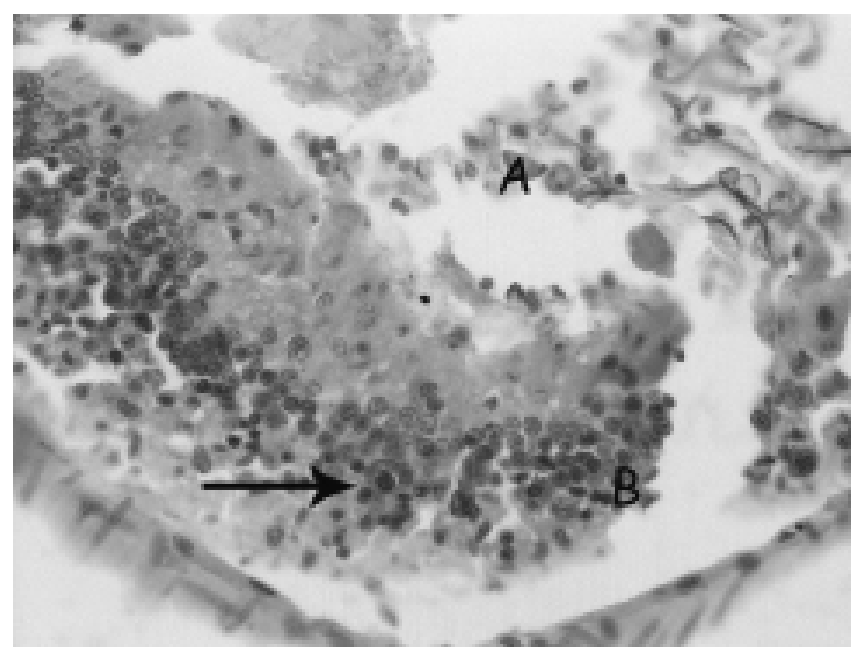

Figura 4 - Fotomicrografia de intestino posterior de girino de rãtouro alimentado com ração de $36 \%$ de PB. Luz intestinal $(A)$ e presença de colite mononuclear (B) e hemossiderina (seta). Coloração com HE, 200X. As mesmas lesões foram observadas nos girinos alimentados com rações contendo 32,45 e $55 \%$ de PB. linfonodo foram observadas nos exemplares examinados (Figuras 3 e 4 ).

Os 48 animais, junto a essa deficiência nutricional ou independentemente dela, apresentavam também processos inflamatórios com focos de células mono e/ou polimorfonucleares no fígado e em outros órgãos (Figuras 5 e 6), como hepatite, enterite, colite, glomerulonefrite. Os processos inflamatórios mais freqüentes foram hepatite mononuclear intersticial, enterite linfocitária, glomerulonefrite mononuclear e gastrite mononuclear, com mucosa tênue, epitélio superficial intacto e a lâmina própria com alguns leucócitos (Figuras 5 e 6). Essas observações são semelhantes às encontradas por Hipolito et al. (2004) e sugerem a ocorrência do mesmo mecanismo de comprometimento nos girinos de rã-touro.

Assim, foram observados casos com glomerulonefrite mononuclear e focos de túbulonefrose, com alterações que afetavam os túbulos proximais e distais com destruição das células epiteliais tubulares sugerindo insuficiência renal. Alguns casos eram acompanhados por infiltração de células mononucleares, fibrose intersticial e, eventualmente, calcificação tubular. Entretanto, essa síndrome hepatorrenal continua sendo um enigma patogenético (Figura 5).

Nos mamíferos a insuficiência hepática pode ocasionar insuficiência renal (Cotram et al., 1989). Além disso, observou-se acúmulo de hemossiderina no intestino posterior (Figura 4) dos animais, que leva ao desenvolvimento de hemossiderose, situação observada também no coração e

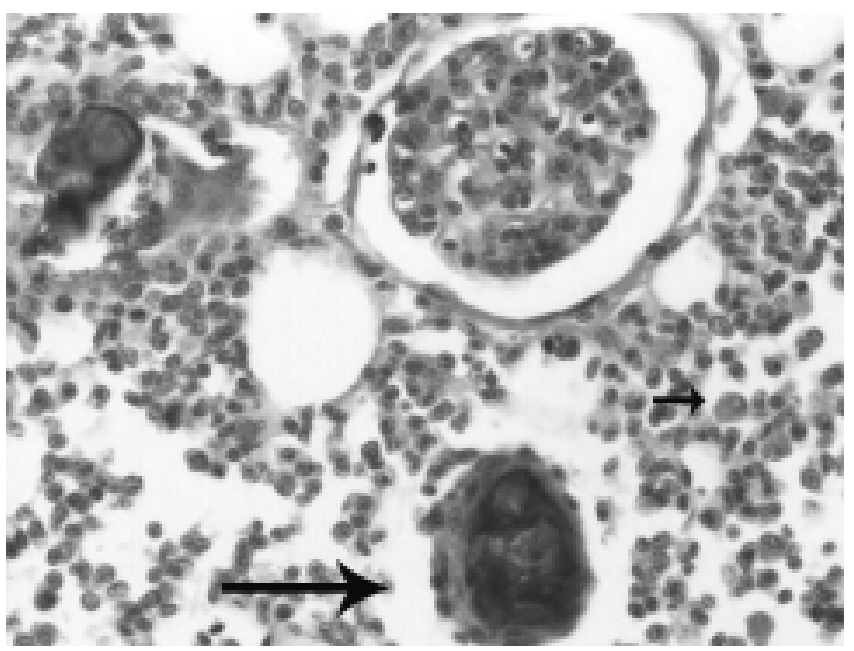

Figura 5 - Fotomicrografia de rim de girino de rã-touro alimentado com ração de $36 \%$ de PB. Presença de calcificação de túbulos renais (seta maior) e de eosinófilos (seta menor). Coloração com HE, 100X. As mesmas lesões foram observadas nos girinos alimentados com rações contendo 32,45 e $55 \%$ de PB. 


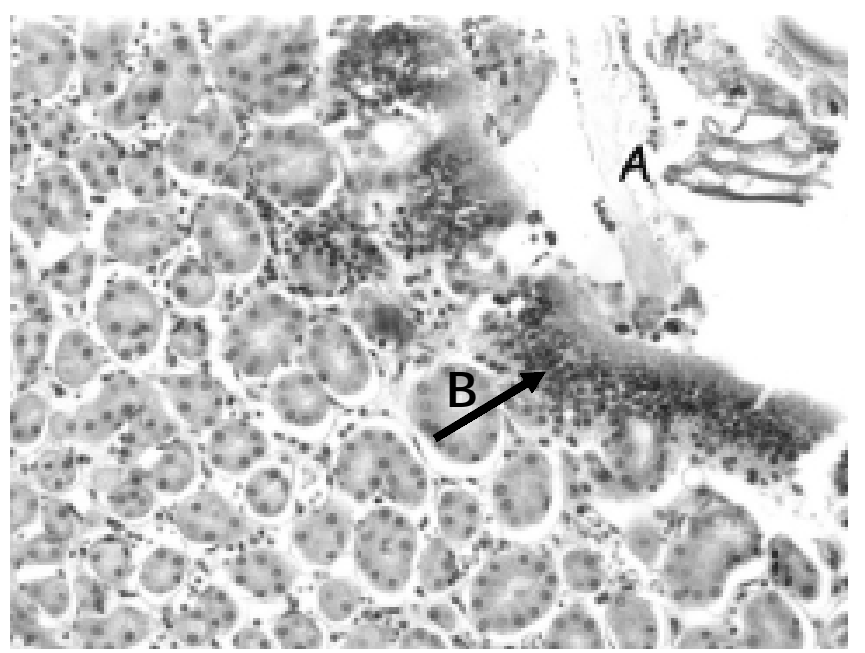

Figura 6 - Fotomicrografia de estômago de girino de rã-touro alimentado com ração de $36 \%$ de PB. Luz estomacal (A) e presença de células linfocitárias (B). Coloração com HE, 100x (As mesmas lesões foram observadas nos girinos alimentados com rações contendo 32,45 e $55 \%$ de PB).

no fígado. A hemossiderina é um pigmento cristalino ou amarelo-dourado a marrom, derivado da hemoglobina, em cuja forma o ferro é armazenado nas células sem as lesar (Cotram et al., 1989).

Os resultados histopatológicos encontrados sugerem que os animais foram alimentados com rações de baixa qualidade protéica, o que comprometeu a sanidade e o desempenho. Pode-se inferir, baseando-se nos achados de Seixas Filho et al. (2006) sobre os aspectos do fígado, que o consumo destas rações pode acarretar acúmulo de nitrogênio oriundo de proteínas não-metabolizadas, o que caracteriza quadro de toxicidade metabólica, corroborando relatos de Boorman(1980).

Considerando a pouca ou nenhuma informação sobre necessidades nutricionais de anfíbios em condições de cultivo semi-intensivo, estudos complementares são necessários para compreensão do comportamento bioquímico desses animais, principalmente na fase de girinos.

\section{Conclusões}

Os achados obtidos neste estudo sugerem que os animais foram alimentados com proteínas de baixo valor biológico, indicando má qualidade das rações, o que comprometeu a sanidade e o desempenho dos animais.

\section{Literatura Citada}

ARRUDA SOARES, H.; FONTANELLO, D.; MANDELLI JR., J. et al. Efeito da densidade de população no ganho de peso de girinos da rã-touro (Rana catesbeiana, Shaw, 1802). Boletim do Instituto de Pesca, v.10, n. único, p.47-51, 1983.

BOORMAN, K.N. Dietary constraints on nitrogen retention. In: BUtTery, P.J.; Linsany, D.B. (Eds.) Protein deposition in animals. London: Butterworths, 1980. p.147-166.

COTRAM, R.; KUMA, V.; ROBINS, S. Patologia - estrutura e função. 4.ed. Rio de Janeiro: Guanabara-Koogan, 1989. $783 \mathrm{p}$.

CULlEY JR., D.D.; MEYRS, S.P.; DOUCETTE JR., A.J. Current status of amphibian culture with emphasis on nutrition, diseases and reproduction of the bullfrog, Rana catesbeiana. In: ANNUAL MEETING OF THE WORD MARICULTURE SOCIETY, 1978, Baton Rouge. Proceedings... Baton Rouge: WMS, 1978. p.653-669.

FONTANELLO, D.; ARRUDA SOARES, H.; MANDELLI JR., J. et al. Crescimento de girinos de Rana catesbeiana, SHAW, 1802 (rã-touro) criadas com rações de diferentes níveis protéicos. Boletim Instituto de Pesca, v.9, n. único, p.125129, 1982.

GOSNER, K.L. A simplified table for staging anuran embryos and larvae with notes on indentication. Herpetologica, v.16, p.183$190,1960$.

GUYTON, A.C.; HALL, J.E. Tratado de fisiologia médica. 4.ed. Rio de Janeiro: Guanabara-Koogan, 2002. 972p.

HIPOLITO, M. Avaliação bioquímica no desenvolvimento da rã-touro Rana catesbeiana (Shaw, 1802) tratada com dieta comercial e experimental. Araraquara: Universidade Estadual Paulista, 2004. 100p. Tese (Doutorado em Biotecnologia) Universidade Estadual Paulista, 2004.

HIPOLITO, M.; LEME, M.C.M.; BACH, E.E. Lesões anátomohistopatológicas em rãs-touro (Rana catesbeiana Shaw, 1802) associadas à deterioração da ração. Arquivos do Instituto de Biologia, v.68, n.1, p.111-114, 2001.

HIPOLITO, M.; MARTINS, A.M.C.R.P.F.; BACH, E.E. Aspectos bioquímicos em fígado de rãs-touro (Rana catesbeiana Shaw, 1802) sadias e doentes. Arquivos do Instituto de Biologia, v.71, n.2, p.147-153, 2004.

SEIXAS FILHO, J.T.; ALMEIDA, L.H.O.; AGUIAR, D.V. et al. Avaliação do trato gastrintestinal em girinos de rã-touro (Rana catesbeiana) submetidos à alimentação com três níveis de proteína bruta em rações comerciais. In: SIMPÓSIO DE ANFÍBIOS DA UNIVERSIDADE FEDERAL DO RIO DE JANEIRO, 2., 2006, Macaé. Anais... Macaé: Universidade Federal do Rio de Janeiro, 2006. p.16.

SEIXAS FILHO, J.T.; PEREIRA MELLO, S.C.R.; FRANQUEIRA, J.M.S. et al. Efeito dos níveis de proteína e energia em rações balanceadas para girinos de rã-touro, Rana catesbeiana (Shaw, 1802) utilizando o peso e o comprimento como parâmetros zootécnicos. Revista Brasileira de Zootecnia, v.27, n.4, p.409-414, 1998.

SEIXAS FILHO, J.T.; ROSTAGNO, H.S.; QUEIROZ, A.C. et al. Avaliação do desempenho de pós-larvas no camarão-de-águadoce Macrobrachium rosenbergii. Revista Brasileira de Zootecnia, v.26, n.4, p.629-637, 1997.

TACON, A.G.J. [1989]. Nutrición y alimentación de peces y camarones cultivados. Disponível em: <http://www.fao.org/ docrep/field/003/ab492s/AB492S05.htm.> Acesso em: 23/2/2006. 